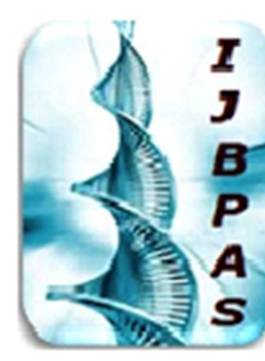

International Journal of Biology, Pharmacy and Allied Seiences (IJBPAS) 'A Bridge Betuen Caboratory and QRendo'

WwW.ijbpas.com

SCIENTOMETRICS: A TOOL TO DESIGN COMPENDIUM OF AYURVEDA RESEARCH

\title{
GONI JM ${ }^{1 *}$ AND TOSHIKHANE HD ${ }^{2}$
}

1: Ayurved Faculty, PhD Scholar, Parul Institute of Ayurved, Parul University, Vadodara, Gujarat, India

2: Dean, Principal, PhD Guide, Parul Institute of Ayurved, Parul University, Vadodara, Gujarat

*Corresponding Author: Jayasheela M Goni: E Mail: jay300672@gmail.com

Received 12 ${ }^{\text {th }}$ Dec. 2021; Revised 14 ${ }^{\text {th }}$ Jan. 2022; Accepted $7^{\text {th }}$ Feb. 2022; Available online $5^{\text {th }}$ March 2022

https://doi.org/10.31032/IJBPAS/2022/11.3.1056

\begin{abstract}
Background; Ayurveda as an ancient system of medicine has imparted knowledge in preventive and curative medicine. In the present scenario, when Ayurveda is totally gaining attention and importance worldwide, there is a need of quality research in Ayurveda. In Ayurveda access for published research is very limited and remote. A scientific review of prior published research papers from e resources gives the direction of present scientific research in Ayurveda field. Scholarly indexed Journals are one of the most important sources of information for scientific research communications and an important link for the advancement of science. Ayurveda novice researchers need a range of Scientometric tools to measure Ayurveda research data. Methodology; Scientometrics has become an essential tool for assessing and analyzing the output of scientists. This article captures existing software tools for Scientometric analysis, aims to review the steps to perform Scientometric Analysis such as data retrieval, performance analysis, science mapping analysis and visualization. Conclusion; The present article discusses that Scientometrics study is a tool to design a compendium of Ayurveda researches. Results of the study give an insight of Ayurveda research scenario to researchers, Clinicians to identify the resource in improvement of the science.
\end{abstract}

Keywords: Scientometrics; Bibliometric; Ayurveda research analysis; Scientometric Tool; Software Tool;

Science mapping analysis; Database; Performance analysis 


\section{INTRODUCTION:}

Ayurveda is a traditional system of medicine of Indian subcontinent that originated in the ancient Vedic times of India. It has an age old history since the 2nd Century BC. (Jaiswal, Y.S., \& Williams, L.L.2016) Ayurveda literally means "The knowledge of life", Knowledge of Ayurveda enables one to understand life is a manifestation of mind, body, soul and spirit, maintaining harmony among all these elements one can achieve longevity and disease free life, (Ravishankar, B., \& Shukla, V. J. 2007), Some of this knowledge can be found in literatures, but much of it is inaccessible. Today Ayurveda is gaining global acceptance, interest in Ayurveda \& its public demand is rapidly increasing. Such demand only be fulfilled by doing more and more advanced research and publishing more research articles in the field of Ayurveda. Recent surveys of the current state of Ayurveda education, Ayurvedic research, publication knowledge, real databases related to Ayurveda available online, and the propensity of Ayurvedic teachers, scholars and students to their status indicate very limited knowledge (Binorkar S, Sawant R, Bhoyar M, et al.2018).

Ayurveda Research Database;
Ayurveda research literature search, continue to be challenging due to the lack of availability of active and dedicated databases. A survey done in 2015 on 46 databases, indicates, AYUSH research portal and Digital Helpline for Ayurveda Research Articles (DHARA) are two major portals for Ayurveda, Annotated Bibliography of Indian Medicine, PubMed, and Directory of Open Access Journals few other Ayurveda databases. ( Aggithaya, M. G., \& Narahari, S. R. 2015). In 1997, M.S. Baghel and K. Girish from Post Graduate Centre for Research in Ayurveda, Jamnagar, has brought publication, "Researches in Ayurveda - A Searchable Directory of Titles of All India Ayurvedic PG And Ph D Theses (Third / Web Edition), updated by three editions. Recently released Ayurvedic Research Data base (ARD) (VII edition, 2001-2018) is also a digital database. The limitation of this database is it is used to see only the previously done unpublished PG/Ph.D. Research Theses Title which is useful for Post Graduates as reference material. (M.S. Baghel, K. Girish 2020), (D.B. Anantha Narayana, Sharanbasappa Durg 2021). Hence, the present article discusses different bibliographic research database and the Scientometrics tool which 
deals with analysis, evaluation and graphic representation of science and technology information.

\section{SCIENTOMETRICS:}

In recent years Scientometric is playing a major role in the measurement and evaluation of research performance Hence the knowledge of Scientometric analysis procedures and its software tools can lead to boost the confidence in aspiring Ayurveda novice researcher. Scientometrics includes all quantitative aspects of the science of science, communication in science, and science policy. These techniques are very useful to identify the research trends in a subject in Ayurveda. Trends in authorship and collaboration in research. There are so many tools and techniques and web analyzing software were developed in this purpose (Hood, W. W., Wilson, C.S. 2001).

In the 1969, Vassily V Nalimov \& Z. M. Mulchenko coined the term Scientometrics. (Nalimov \& Mulchenko, 1969b), This term is used to study growth, structure, interrelationships and productivity of science. Scientometrics is the study of measuring and analyzing science, technology and innovation (Hood, W. W., Wilson, C.S. 2001). Scientometric analysis is an information and technology tool. It deals with analysis, evaluation and graphic representation of science and technology information, Nalimov \& Mulchenko (1969a), Nalimov (1970) and Nalimov et al. (1971). It tells "Who is doing what and where?" The word Scientometric emerges from two significant word- science and metrics- metrics used for quantitative analysis of researcher contribution to various scientific domains ( $\mathbf{V}$. Jayasree, M.D. Baby, 2019). Major research issues include the measurement of impact, reference sets of articles to investigate the impact of journals and institutes, understanding of scientific citations and mapping scientific fields (Loet

\section{Leydesdorff, Staša Milojević 2013).}

There are two major procedures in Scientometrics, performance analysis and science mapping. Performance analysis aims to evaluate different scientific actors like researchers, institutions, countries, etc, based on publications and citations data (Narin,Francis;

Hamilton,Kimberly S,1996). Science Mapping Analysis aims at displaying the structural and dynamic aspects of scientific research. A science map is used to represent the cognitive structure of a research field. Cobo, Manuel J.; LópezHerrera, Antonio G.; Herrera-Viedma, Enrique; Herrera, Francisco, (2011a); Small, Henry, (1999) 
The present article aims to explain the steps to perform Scientometric Analysis and different software tools used to perform Scientometric analysis;

\section{Database for Scientometric analysis}

2. Performance analysis

3. Science Mapping analysis and visualization

\section{DATABASE FOR SCIENTOMETRIC} ANALYSIS

The Scientometric analysis requires, best data source that fits with the scientific coverage of our research area and best Database that allows downloading research data in different formats such as, full-text articles, book series, most peer-reviewed online academic journals, reviews, editorials, chronologies, abstracts, conference papers, thesis, preprints, technical reports, court opinions and patents, grants, clinical trials, and policy papers.

Following are the few Databases available; ISI Web of

Science(WoS)(http://www.webofknowledge. com),Scopus(http://www.scopus.com), GoogleScholar(GS)(http://scholar.google.co m),PubMed(http://www.ncbi.nlm.nih.gov/pu bmed).

Web of Science and Scopus are websites that provides access to multiple databases and citation data specially for science are accessible only on subscription. Google Scholar and Pubmed are freely available website (Moral-Muñoz, José A; HerreraViedma, Enrique; Santisteban-Espejo, Antonio; Cobo, Manuel J. 2020). Few other data bases, Digital Bibliography \& Library Project(DBPL;http://dblp.unitrier.de/),

Astrophysics Data System

(ADS; http://adswww.harvard.edu/), Science Direct (http://www.sciencedirect.com/), Patent data from the United States Patent and Trademark Office (USPTO; http://www.uspto.gov/) or the Derwent Innovations Index provided by ISI WoS. Funding data can be downloaded from the National Science Foundation (http://www.nsf.gov/), There are other bibliographic sources such as: arXiv (http://arxiv.org), CiteSeerX (http://citeseerx.ist.psu.edu/), (Cobo, M., López, Herrera, A., Herrera, Viedma, E. and Herrera, F. 2011),

\section{PERFORMANCE ANALYSIS:}

Once the required data is obtained the next step is to conduct the performance analysis process. Performance analysis aims at evaluating groups of countries, universities, departments, researchers in scientific research field and the impact of their activity. In this process, the tools like, CR Explorer and Publish or Perish, ScientoPyUI are used 
to get the information about the production and impact of a specific research area. (Moral-Muñoz, José A.; Herrera-Viedma, Enrique; Santisteban-Espejo, Antonio; Cobo, Manuel J.2020)

Performance analysis tools are;

CRExplorer Software; This tool is 1.9 Analyzed version,2018, developed by Hochshule fur Telekommunikation Leipzig(HfTL) with operative system Java.This software primarily helps for obtaining Reference Publication Year Spectroscopy (RPYS) Marx, Werner; Bornmann, Lutz; Barth, Andreas; Leydesdorff, Loet (2014). It is also used for analysis of citations, average, above average and below average for each year, it allows to identify publication not cited for long period followed by a sudden spike of popularity called as sleeping beauty (Van-Raan, Anthony F. J. 2004b). It is indicated for analysis of the cited references of a publication collection downloaded from WoS database, Scopus or Crossref (Thor; Marx; Leydesdorff; Bornmann, 2016).

Publish or Perish Software; This tool is 7 Analyzed version, 2019, developed by Melbourne-based Tarma Software Research Pty Ltd with operative system Win, Mac and Linux. This software primarily helps for obtaining $\mathrm{H}$-index from Google Scholar, it allows to perform searches directly from databases of Google Scholar, Web of Science, Scopus, MA and Crossref, this provides performance analysis of the core documents derived from indicated source. Finally, output is exported to Bibtex, CSV, EndNote and ISI Export. (Harzing, 2008; Harzing; Van-der-Wal, 2008)

Sciento PyUI: This tool is 1.4.0 Analyzed version, 2019, developed by University of Cauca with operative system Phyton. (RuizRosero; Ramírez-González; ViverosDelgado, 2019) This tool is used to import WoS and Scopus data set, filter research type, author's name normalization, duplicate removal, citation number, extraction of country and institutions from author affiliations. ScientoPy adds some performance indicators to the topics analyzed, such as average growth rate, average document per years and percentage of documents in the last years from the Database WoS and Scopus, also used in visualization of timeline, horizontal bars, horizontal bar trends, evolution and word cloud (Moral-Muñoz, José A.; HerreraViedma, Enrique; Santisteban-Espejo, Antonio; Cobo, Manuel J.2020).

3. SCIENCE MAPPING ANALYSIS AND VISUALIZATION: 
Science mapping aims at displaying the structural and dynamic aspects of scientific research It represents the cognitive structure of a research field. Börner, Chen, \& Boyack, (2003); Morris \& Van Der Veer Martens, (2008); Noyons, Ed C. M.; Moed, Henk F.; Van-Raan, Anthony F. J. (1999). Scientific maps representing the relationship among the different actors like authors, institutions, countries, disciplines, fields, specialties etc. (Small, Henry. 1999). Researchers usually have to use more than one software tools. Either nonspecific science mapping software e.g., Pajek, Gephi, or UCINET or specific science mapping software tools e.g., CoPalRed, SciMAT, Science of Science Tool, or VOSviewer. A list of software tools widely used in the literature can be found in Cobo, LópezHerrera, Herrera-Viedma, and Herrera (2011b).

\section{Science Mapping tools are;}

Bibexcel: This software is used to create data files that can be imported to Excel, developed by Olle Persson at University of Umeä, Sweden. The main characteristic of this software is the flexibility, it can retrieve information from various bibliographic sources WoS, Scopus etc. Once the data is normalized this tool is mainly used to create different co-occurrence matrices co-citation, bibliographic coupling, co-author, and coword. Bibexcel tool is used for deletion of low recurrence items and keeping just the strongest links. The exported Data is visualized, using external software like Pajek (Batagelj; Mrvar, 2004), SPSS or VOSviewer (Van-Eck; Waltman, 2010).

Biblioshiny: It is web-based graphical interface, powered by Bibliometrix, It was developed by Massimo Aria and Corrado Cuccurullo from the University of Naples and University of Campania's Luigi Vanvitelli (Italy). It mainly works with WoS, Scopus and Dimensions data. The graphs and performance analyses generated from this tool can be exported to several kinds of file formats; maps can be exported to Pajek and html, and tables can be copied to the clipboard or saved as Excel, pdf or printed. (Aria; Cuccurullo, 2017)

BiblioMaps: It is web-based graphical interface, run under python, developed by author, Sébastian Grauwin (Grauwin; Jensen, 2011). It works with WoS and Scopus data. The tool used for Data acquisition, Data preprocessing, Data analysis, Data visualization, the output can be visualized in BiblioMaps or exported to other software.

CiteSpace: This tool is useful in analysis and visualization of emerging trends and patterns 
in a research area or knowledge domain, developed at Drexel University (USA). (Chen, 2006; Chen, 2019). This tool works with different bibliographic databases, such as WoS, Scopus, and Chinese Social Science Citation Index(Cssci). Authors' geographic locations, links to their collaborators can be mapped using Google earth.

CitNetExplorer: This tool was developed by the Centre for Science and Technology Studies (CWTS) at Leiden University (The Netherlands). This tool works with different bibliographic databases, such as WoS, Scopus. It is a software tool for visualizing and analyzing citation networks, based on the algorithmic historiography designed by Garfield, to know citation relation between two publications. (Garfield; Pudovkin; Istomin, 2003).

SciMAT: This tool was developed by the Secaba Lab at University of Granada (Spain), and it is now updated and maintained by the IntellSOK group at University of Cadiz (Spain). It is an open-source Science Mapping Analysis(SMA) software. It supports the analyst to carry out all the different steps, from the data loading to the visualization and interpretation of the output. It gives details of sum, maximum, minimum, and average citations of articles using advanced bibliometric indexes such as the h- index (Hirsch, 2005; Alonso; Cabrerizo; Herrera-Viedma;Herrera, 2009), G-index (Egghe, 2006), HG-index

(Alonso; Cabrerizo; Herrera-Viedma; Herrera, 2010) and q2-index(Cabrerizo; Alonso; Herrera-Viedma; Herrera, 2010). Different visualization techniques such as research strategic diagram, cluster network, evolution map, and overlapping map are available in SciMAT. Cobo, Manuel J.; LópezHerrera, Antonio G.; Herrera-Viedma, Enrique; Herrera, Francisco (2012).

Sci2 Tool: This tool was developed by Cyberinfrastructure for Network Science Center at Indiana University(USA). This tool works with different bibliographic data formats, such as WoS, Scopus, GS, Bitext, EndNote, Facebook, research funding from the National Science Foundation and National Institutes of Health, as well as other academic data in CSV format. Sci2 tool is used in Data acquisition and processing, Data analysis, Modeling and Layout. (Börner; Chen; Boyack, 2003)This tool obtains the following bibliometric networks: co-author, co-PI (Principal Investigator), documents cocitation, journals co-citation, authors cocitation, bibliographic coupling, author bibliographic coupling and journals bibliographic coupling. Moral-Muñoz, José 


\section{A.; López-Herrera, Antonio G.; Herrera-} Viedma, Enrique; Cobo, Manuel J. (2019)

VOSviewer: It was developed by the Centre for Science and Technology Studies (CWTS) at Leiden University (The Netherlands). This tool works with different bibliographic data formats, such as WoS, Scopus, Dimensions, PubMed. VOSviewer is a software tool designed for constructing and visualizing bibliometric networks, with journals, researchers or individual publications as actors, and based on co-citation, bibliographic coupling, or co-authorship relations, it also constructs the map based on a co-occurrence matrix (Van-Eck; Waltman, 2010)

\section{DISCUSSION:}

Scientometrics has become an important tool for evaluating and analyzing the results of researchers, the cooperation between institutions and authors, and the impact of government funding on national R\&D performance and educational efficiency. Hence, professionals, and scientists need scientific tools to measure research data. This article aims to provide various software tools and different steps that can be used for bibliometric and Scientometric analysis, including data collection, performance analysis, and visualization.
In the first step, Data acquisition, instead of commercial search engine database, Research Database provides more option and powerful search tools for narrowing results to get the information more quickly. The researcher can find peer reviewed scholarly articles written by credible authors, researchers, and expert in their field. Research database offers access to thousands of articles, books, conference papers, thesis, grants, patents, and more.

The second step, Performance analysis provides the indicators that the Ayurveda researcher can utilize for their scientific evaluation. CR Explorer software tool, helps frequency with which references are cited in the publications of a specific Ayurveda research field, also helps in understanding the scope and trend of the research work. With the help of Publish or Perish software tool, researcher can retrieve research topic through author name, publication date, topics, keywords and also analyze research citations specially in Google scholar database and Microsoft Academic Search, Finally, output can be exported to Bibtex, CSV, EndNote and ISI Export. It's an ideal software for gathering information for dissertations research papers and more. ScientoPyUI software tool, helps researcher in extracting top topics in selected research 
area it also imports author name, publication name, research area, author key words, type of document, author country and institution, it finds and removes duplicated documents in research literature review.

The third step is Science mapping analysis, it is a data visualization tool helps the Ayurveda researcher to compare their work to current research trends and it also extends researchers field of vision, understand the lacuna, map future path of study. Bibexcel software tool, helps to import the research data to excel form, this will help the researcher to do analysis using SPSS or VOSviewer. CiteSpace software tool, helps researcher in visualizing and analyzing trends and patterns in the scientific literature, understanding network of research and historical patterns, such as the growth of a topic area, international collaboration. CitNetExplorer software tool helps to analyze the development of a research field over time, identifying the literature on a research topic, it also shows how the researcher has influenced the other researcher. SciMAT software tool, helps in Identification of the significant participation countries in India's international collaboration in Ayurveda research, Productivity and impact of leading institutions and authors contribution to research in India. Sci2 Tool, helps in analyzing individual, local and global level research networking. VOSviewer software Tool, it has a fantastic visualization of coauthorship networks and citation networks. It is capable of loading and exporting information from many sources.

\section{CONCLUSION:}

In this article, a brief analysis of the most important Scientometric techniques and software used brought to light, highlighting their importance in research valuation. If these scientific measurement techniques incorporated into Ayurveda research, the main result is to understand the quantitative and qualitative assessment of the growth of global Ayurveda research. The other results are to know India's contribution, year wise growth of publication, author's productivity, citation impact of other countries, identification of the most participation countries in India's international collaboration in Ayurveda research. Also, learn about the productivity and impact of leading institutions, and their contributions to Ayurveda research in India. Moreover, Scientometric analyses is helpful for learning the history and current status of a study field. Novice researchers in Ayurveda need this kind of Scientometric analysis of the research field annotations to conduct research in 
Ayurveda. Hence, the results of

Scientometric research provide researchers with insights into Ayurveda research scenarios to identify scientific improvements.

\section{REFERENCES}

[1] Aggithaya, M. G., \& Narahari, S. R. (2015). Literature searches on Ayurveda: An update. Ayu, 36(3), $238-253$.

https://doi.org/10.4103/0974-

\section{$\underline{8520.182754}$}

[2] Alonso, Sergio; Cabrerizo, Francisco-Javier; Herrera-Viedma, Enrique; Herrera, Francisco (2009). "h-index: A review focused in its variants, computation and standardization for different scientific fields". Journal of informetrics, v. 3, n. $4, \quad$ pp. 273-289. https://doi.org/10.1016/j.joi.2009.04.0 $\underline{01}$

[3] Alonso, Sergio; Cabrerizo, Francisco-Javier; Herrera-Viedma, Enrique; Herrera,

Francisco (2010). "hg-index: A new index to characterize the scientific output of researchers based on the hand g-indices". Scientometrics, v. 82, n. 2 , pp.391-400.

https://doi.org/10.1007/s11192-009$\underline{0047-5}$
[4] Aria, Massimo; Cuccurullo, Corrado (2017). "Bibliometrix: An R-tool for comprehensive science mapping analysis". Journal of informetrics, v. 11, n. 4, pp. 959-975. https://doi.org/10.1016/j.joi.2017.08.0 $\underline{07}$

[5] Batagelj, Vladimir; Mrvar, Andrej (2004). "Pajek - Analysis and visualization of large networks". Graph drawing software SE - 4, pp. 77-103. Springer Berlin Heidelberg. ISBN: $\begin{array}{lllll}978 & 3 & 642 & 62214 & 4\end{array}$ https://doi.org/10.1007/978-3-642$\underline{18638-7 \quad 4}$

[6] Binorkar, Sandeep \& Sawant, Ranjeet \& Bhoyar, Manish \& Parlikar, Gajanan. (2018). Ayurveda Education \& Research in India-Present scenario, Challenges \& Solutions. International Journal of Complementary \& Alternative Medicine. $\quad 1$ 130-137. DOI:10.15406/ijcam.2018.11.00362. https://www.researchgate.net/publicat ion/323599785 Ayurveda_Education Research_in_India-

Present_scenario_Challenges_Solutio $\underline{\mathrm{nS}}$

[7] Börner, Katy; Chen, Chaomei; Boyack, Kevin W. (2003). 
"Visualizing knowledge domains".

Annual review of information science and technology, v. 37, n. 1, pp. 179255.

https://doi.org/10.1002/aris.14403701 $\underline{06}$

[8] Cabrerizo, Francisco-Javier; Alonso, Sergio; Herrera-Viedma, Enrique; Herrera, Francisco (2010). "q2-Index: Quantitative and qualitative evaluation based on the number and impact of papers in the Hirsch core". Journal of informetrics, v. 4, n. 1, pp. 23-28. https://doi.org/10.1016/j.joi.2009.06.0 $\underline{05}$

[9] Chen, Chaomei (2006). "CiteSpace II: Detecting and visualizing emerging trends and transient patterns in scientific literature".Journal of the American Society for Information Science and Technology, v. 57, pp. 359-377.

\section{https://doi.org/10.1002/asi.20317}

[10] Chen, Chaomei (2017). "Science mapping: A systematic review of the literature". Journal of data and information science, v. 2, n. 2, pp. 140. https://doi.org/10.1515/jdis$\underline{\text { 2017-0006 }}$
[11] Cobo, M., López-Herrera, A., Herrera-Viedma, E. and Herrera, F. (2011). Science mapping software tools: Review, analysis, and cooperative study among tools. J. Am. Soc. Inf. Sci., 62: 13821402. https://doi.org/10.1002/asi.21 $\underline{525}$

[12] Cobo, Manuel J.; López-Herrera, Antonio G.; Herrera-Viedma, Enrique; Herrera, Francisco(2011a). "Science mapping software tools: Review, analysis, and cooperative study among tools". Journal of the American Society for Information Science and Technology, v. 62, n. 7, pp. 1382-1402. https://doi.org/10.1002/asi.21525

[13] Cobo, Manuel J.; López-Herrera, Antonio G.; Herrera-Viedma, Enrique; Herrera, Francisco (2011b). “An approach for detecting, quantifying, and visualizing the evolution of a research field: A practical application to the fuzzy sets theory field". Journal of informetrics, v. 5, n. $1, \quad$ pp. 146-166. https://doi.org/10.1016/j.joi.2010.10 .002 
[14] Cobo, Manuel J.; López-Herrera, Antonio G.; Herrera-Viedma, Enrique; Herrera, Francisco (2012). "SciMAT: A new science mapping analysis software tool". Journal of the American Society for Information Science and Technology, v. 63, n. 8, pp. 16091630.

https://doi.org/10.1002/asi.22688

[15] D.B. Anantha Narayana, Sharanbasappa Durg (2021). Ayurveda: (W)here is the evidence, Journal of Ayurveda and Integrative Medicine,Volume 12, Issue 2,2021, Pages 408-

411,ISSN09759476, https://doi.org/1 0.1016/j.jaim.2020.07.001. https://www.sciencedirect.com/scien ce/article/pii/S0975947620300590

[16] E. C. M. Noyons, H. F. Moed, A. F. J. Vanraan, (1999), "Integrating research performance analysis and science mapping", Scientometrics, jointly published by Elsevier Science Ltd, Oxford and Akademiai Kiad6, Budapest, Vol. 46 (3), 591604.

https://ideas.repec.org/a/spr/scient/v 46y1999i3d10.1007_bf02459614.ht $\underline{\mathrm{ml}}$
[17] Egghe, Leo (2006). "Theory and practise of the g-index". Scientometrics, v. 69, pp. 131-152. https://doi.org/10.1007/s11192-0060144-7

[18] Garfield, Eugene; Pudovkin, Alexander I.; Istomin, Vladimir S. (2003). "Why do we need algorithmic historiography?"Journal of the American Society for Information Science and Technology, v. 54, n. 5, pp. 400412.https://doi.org/10.1002/asi.1022 6

[19] Grauwin, Sebastian; Jensen, Pablo (2011). "Mapping scientific institutions". Scientometrics, v. 89, article 943.https://doi.org/10.1007/s11192011-0482-y

[20] Harzing, Anne-Wil (2008). "Reflections on the h-index". https://harzing.com/publications/whi te-papers/reflections-on-the-h-index

[21] Harzing, Anne-Will K.; Van-derWal, Ron (2008). "Google Scholar as a new source for citation analysis". Ethics in science and environmental politics, v. 8, n. 1, pp. 61-73.

https://doi.org/10.3354/esep00076 
[22] Hirsch, Jorge E. (2005). "An index to quantify an individual's scientific research output". Proceedings of the National Academy of Sciences of the United States of America, v. 102, n. 46, pp. 16569-16572. https://doi.org/10.1073/pnas.050765 $\underline{5102}$

[23] Hood, W.W. Wilson, C.S. (2001). The literature of bibliometrics, scintometrics, and informetrics, Vol. 52, No. 2 (2001) 291-314. https://doi.org/10.1023/A:10179199 24342

[24] Jaiswal, Y. S., \& Williams, L. L. (2016). A glimpse of Ayurveda The forgotten history and principles of Indian traditional medicine. Journal of traditional and complementary medicine, 7(1), 5053.

https://doi.org/10.1016/j.jtcme.2016. $\underline{02.002}$

[25] Jayasree, V., \& Baby, M. D. (2019). Scientometrics: Tools, Techniques and Software for Analysis. Indian Journal of Information Sources and Services, 9(2), 116-121. https://doi.org/10.51983/ijiss.2019.9 .2 .611
[26] Loet Leydesdorff, Stasa Milojevic (2013). "Scientometrics" Cornell University Libraries. https://arxiv.org/abs/1208.4566

[27] Marx, Werner; Bornmann, Lutz; Barth, Andreas; Leydesdorff, Loet (2014). "Detecting the historical roots of research fields by reference publication year spectroscopy (RPYS)". Journal of the Association for Information Science and Technology, v. 65, n. 4, pp. 751-764.

https://doi.org/10.1002/asi.23089

[28] M.S. Baghel, K. Girish (2020). Home | Researches in ayurvedaonline directory of $\mathrm{PG}$ and $\mathrm{PhD}$ titles. https://www.researches-inayurveda.co.in/, Accessed 5th May 2020 Google Scholar

[29] Moral-Muñoz, José A.; LópezHerrera, Antonio G.; HerreraViedma, Enrique; Cobo, Manuel J. (2019). "Science mapping analysis software tools: A review". Springer handbook of science and technology indicators, pp. 159-185. https://doi.org/10.1007/978-3-03002511-3_7

[30] Moral-Muñoz, José A.; HerreraViedma, Enrique; Santisteban- 
Espejo, Antonio; Cobo, Manuel J. (2020). "Software tools for conducting bibliometric analysis in science: An up-to-date review". El profesional de la información, v. 29, n. 1, e290103.

\section{https://doi.org/10.3145/epi.2020.ene} .03

[31] Morris, Steven \& Martens, Betsy. (2008). Mapping research specialties. ARIST. 42. 213-295. 10.1002/aris.2008.1440420113.

[32] Nalimov, V. V., Z. M. Mulchenko (1969a), Eshche raz $\mathrm{k}$ voprosu o kontseptsii eksponentsial'nogo rosta. [A word to add on the exponential growth concept.] NauchnoTekhnicheskaya Informatsiya. Seriya 2. 8 : 12-14. [English translation in: Automatic Documentation and Mathematical Linguistics. 3 (1969) 37-40.]

[33] Nalimov, V. V., Z. M. Mulchenko (1969b), Naukometriya. Izuchenie Razvitiya Nauki kak Informatsionnogo Protsessa. [Scientometrics. Study of the Development of Science as an Information Process], Nauka, Moscow, (English translation: 1971. Washington, D.C.: Foreign
Technology Division. U.S. Air Force Systems Command, WrightPatterson AFB, Ohio. (NTIS Report No.AD735-634).

[34] Nalimov, V. V. (1970), Influence of mathematic statistics and cybernetics on the methodology of scientific investigations, Zavodskaya Laboratoriya, 36 (10) : 1218-1226. [English translation in Industrial Laboratory, 36 (10): 1549-1558.]

[35] Nalimov, V. V., I. V. Korodon, A. YA. Korneeva (1971), Geograficheskoe Raspredelenie Nauchnoi Informatsii. [Geographic Distribution of Scientific Information.] Informatsionnye Materialy. Moscow: an SSSR Nauchnyi Sovet po Kompleksnoi Probleme Kibernetiki. [Informational Papers. Moscow: Soviet Academy of Science, Scientific Council on Cybernetics.] 2 : 3-37. [English translation in: V. V. NALIMOV, Faces of Science. Philadelphia, Institute for Scientific Information, 1981， 237-260 (chapter 11).]

[36] Narin, Francis; Hamilton, Kimberly S. (1996). "Bibliometric 
performance

measures".

Scientometrics, v. 36, pp. 293-310.

https://doi.org/10.1007/BF02129596

[37] Noyons, Ed C. M.; Moed, Henk F.;

Van-Raan, Anthony F. J. (1999).

"Integrating research performance analysis and science mapping". Scientometrics, v. 46, pp. 591-604. https://doi.org/10.1007/BF02459614

[38] Ravishankar, B., \& Shukla, V. J. (2007). Indian systems of medicine: a brief profile. African journal of traditional, complementary, and alternative medicines:

AJTCAM, 4(3), 319-337. https://doi.org/10.4314/ajtcam.v4i3. $\underline{31226}$

[39] Ruiz-Rosero, Juan; RamírezGonzález, Gustavo; ViverosDelgado, Jesús (2019). "Software survey: ScientoPy, a scientometric tool for topics trend analysis in scientific publications". Scientometrics, v. 121, n. 2, pp. 1165-1188.

https://doi.org/10.1007/s11192-01903213-w

[40] Small, Henry (1999). "Visualizing science by citation mapping". Journal of the American Society for Information Science, v. 50, n. 9, pp.
799-813.

https://doi.org/10.1002/(SICI)10974571(1999)50:93.0.CO;2-G

[41] Thor, Andreas; Marx, Werner; Leydesdorff, Loet; Bornmann, Lutz (2016). "Introducing CitedReferencesExplorer

(CRExplorer): A program for reference publication year spectroscopy with cited references standardization". Journal of Informetrics, v. 10, n. 2, pp. 503515.

https://doi.org/10.1016/j.joi.2016.02 .005

[42] Van-Eck, Nees-Jan; Waltman, Ludo (2010). "Software survey: VOSviewer, a computer program for bibliometric mapping”. Scientometrics, v. 84, n. 2, pp. 523538.

https://doi.org/10.1007/s11192-0090146-3

[43] Van-Raan, Anthony F. J. (2004b). "Sleeping beauties in science". Scientometrics, v. 59, n. 3, pp. 467472.https://doi.org/10.1023/B:SCIE. $\underline{0000018543.82441 . f 1}$ 